\title{
PENGARUH PRODUKSI KAYU BULAT DAN JUMLAH IPHHK TERHADAP PRODUKSI KAYU GERGAJIAN DI PROVINSI MALUKU
}

\author{
Umi Salam M. Nur ${ }^{1}$ Agus Kastanya ${ }^{2}$, Rohny Maail $^{3}$ \\ Program Pascasarjana Program Studi Manajemen Hutan Universitas Pattimura \\ Korespondensi Email : umisalam42@yahoo.co.id \\ \begin{tabular}{|l|l}
\hline Diterima : 5 September 2017 & Disetujui : 20 Oktober 2017
\end{tabular}
}

\section{Intisari}

Upaya peningkatan pemanfaatan hasil hutan diwujudkan dalam bentuk industri pengolahan hasil hutan yang disebut sebagai industri primer hasil hutan. Total luas hutan di Provinsi Maluku adalah 3.919.701 Ha. Potensi hutan alam produksi mengalami penurunan yang cukup signifikan. Kondisi ini tentu saja berpengaruh pada jumlah kayu bulat yang dihasilkan, dengan kata lain produksi kayu bulat juga mengalami penurunan. Di lain pihak, permintaan kayu di Maluku sangat tinggi diindikasikan dengan tingginya kapasitas industri yang ada. Kondisi ini tidak mendukung bagi keberlangsungan industri kayu. Penelitian ini bertujuan untuk: 1) Mengetahui produksi hasil hutan kayu berdasarkan study kasus yang dilakukan di Provinsi Maluku. 2) menganalisis pengaruh jumlah produksi kayu gergajian dan jumlah IPHHK terhadap produksi kayu gergajian. Hasil penelitian menunjukkan bahwa Jumlah IPHHK di Provinsi Maluku tahun 2017 sebanyak 80 unit badan usaha industri, primer yang aktif melakukan proses pengelolaan kayu olahan sebanyak 57 unit. Hasil analisa regresi linier terlihat bahwa Karena Fhitung $\geq$ Ftabel, 0,723 $>0,457$, maka $\mathrm{H}_{0}$ ditolak, artinya ada pengaruh secara siqnifikan/nyata antara jumlah produksi kayu bulat, jumlah IPHHK secara bersama-sama terhadap produksi kayu gergajian.

Kata Kunci : Produksi kayu bulat, gergajian, Regresi linier.

\begin{abstract}
Efforts to increase the utilization of forest products are realized in the form of forest product processing industries which are referred to as primary forest product industries. The total forest area in Maluku Province is 3,919,701 Ha. The potential of natural forest production has decreased significantly. This condition certainly affects the amount of roundwood produced, in other words, the production of round wood has also decreased. On the other hand, the demand for wood in Maluku is very high indicated by the high capacity of existing industries. This condition does not support the sustainability of the timber industry. This research was carried out with the aim of 1) Knowing the production of timber forest products based on a case study conducted in Maluku Province. 2) analyze the effect of sawn timber production and the number of IPHHK on sawn timber production. The result of research show that the number of IPHHK in Maluku Province in 2017 is 80 units of industrial enterprises, the primary of which is active in the process of processing processed wood as much as 57 units. The results of linear regression analysis, it can be seen that because Fcount 7 Ftable, 0.723> 0.457, then $\mathrm{H} 0$ is rejected, meaning that there is a significant influence between the amount of round wood production, the number of IPHHK together for sawn timber production.
\end{abstract}

Keywords: Production of logs, sawn, linear regression

\section{PENDAHULUAN}

Pemanfaatan hasil hutan adalah

kegiatan pengelolaaan hasil hutan yang ditujukan untuk meningkatkan nilai hasil hutan dan efisiensi bahan baku yang dilakukan melalui pemberian izin usaha industri ataupun izin usaha perluasan industri. Upaya peningkatan nilai ini diwujudkan dalam bentuk industri pengolahan hasil hutan yang disebut sebagai 
industri primer hasil hutan. Kegiatan dalam industri primer hasil hutan dibedakan menjadi dua jenis, yaitu industri untuk hasil kayu dan industri untuk hasil non kayu. Sebelum masuk industri pengolahan, suatu hasil hutan harus disertai dengan dokumen yang menerangkan asal kayu dan non kayu yang dikeluarkan oleh pejabat yang berwenang. Hal ini dilakukan guna terwujudnya tertib tata usaha hasil hutan.

Tata cara pengajuan izin usaha industri primer hasil hutan, dapat dikelompokkan dalam jenis industri primer hasil hutan kayu yang terdiri dari: a) Pengolahan kayu bulat menjadi kayu gergajian, b) pengolahan kayu bulat dan atau bahan baku serpih menjadi serpih kayu, veneer, kayu lapis, laminating veneer lumber c) pengolahan kayu bulat atau bahan baku serpih menjadi kayu gergajian; serpih kayu, veneer dan kayu lapis, laminating veneer lumber, dan d) industri selain yang dimaksud dalam kelompok a, b dan c.

Sementara pada industri primer hasil hutan bukan kayu, jenis industrinya dapat berupa pengolahan bahan baku bukan kayu dengan skala besar, menengah dan kecil.

Dalam hal kegiatan pengelolaan hutan maupun pengolahan hasil hutan, pemberian izin bagi seluruh proses dan kegiatan tersebut berkaitan dengan kewenangan yang dimiliki masing-masing pemerintah daerah. Kewenangan pemberian izin dapat dikatakan bahwa :
1) Pemerintah Daerah Kabupaten (untuk wilayah kabupaten), berwenang untuk mengeluarkan : Izin usaha pemanfaatan kawasan; Izin usaha pemanfaatan jasa lingkungan; Izin usaha pemanfaatan hasil hutan bukan kayu (pada hutan alam dan/atau hutan tanaman); dan Izin pemungutan hasil hutan bukan kayu.

2) Pemerintah daerah Provinsi (untuk wilayah antar kabupaten), berwenang untuk mengeluarkan : Izin usaha pemanfaatan kawasan; Izin usaha pemanfaatan jasa lingkungan; Izin usaha pemanfaatan hasil hutan bukan kayu (pada hutan alam dan/atau hutan tanaman); Izin pemungutan hasil hutan bukan kayu

3) Pemerintah pusat (untuk wilayah antar provinsi), berwenang untuk mengeluarkan : Izin usaha pemanfaatan kawasan; Izin usaha pemanfaatan jasa lingkungan; dan Izin usaha pemanfaatan hasil hutan bukan kayu (pada hutan alam).

Total luas hutan di Provinsi Maluku adalah 3.919.701 Ha. Luas kawasan hutan tersebut telah memenuhi luas minimum sebagaimana yang dipersyaratkan (minimum $30 \%$ luas daratan), dimana $73,03 \%$ dari total luas hutan adalah hutan produksi. Potensi hutan alam produksi mengalami penurunan yang cukup signifikan (Dinas Kehutanan Provinsi Maluku, 2016). Kondisi ini tentu saja berpengaruh pada jumlah kayu bulat yang dihasilkan, dengan kata lain produksi 
kayu bulat juga mengalami penurunan. Di lain pihak, permintaan kayu di Maluku sangat tinggi diindikasikan dengan tingginya

Penelitian ini dilaksanakan dengan tujuan untuk : 1) Mengetahui produksi hasil hutan kayu berdasarkan studi kasus yang dilakukan di Provinsi Maluku, dan

\section{METODE PENELITIAN}

\section{Lokasi dan Waktu Penelitian}

Penelitian ini dilaksanakan di Kota Ambon dan sekitarnya serta lingkup Dinas Pertanian dan Kehutanan Kota Ambon dan Dinas Kehutanan Provinsi Maluku,selama tiga bulan pada bulan Maret - Mei Tahun 2017.

\section{Rancangan Penelitian}

Penelitian ini termasuk penelitian deskriptif kuantitatif yang bertujuan menjelaskan, meringkas berbagai kondisi, situasi dan berbagai variabel yang menjadi objek peneliitian berdasarkan apa yang terjadi.

\section{Variabel Penelitian}

Variabel-variabel yang digunakan dalam penelitian ini adalah

1) Variabel independen (Eksogen) adalah variabel yang mempengaruhi atau menjadi penyebab bagi variabel endogen. Adapun variabel eksogen adalah :

\section{Analisis Data}

Analisis regresi linier berganda adalah regresi linier untuk menganalisis kapasitas industri yang ada. Kondisi ini tidak mendukung bagi keberlangsungan industri kayu

menganalisis pengaruh jumlah produksi kayu gergajian dan jumlah IPHHK terhadap produksi kayu gergajian

\section{Bahan dan Alat Penelitian}

Bahan penelitian yang diperlukan yakni data pengamanan dan pengawasan hutan dari Instansi tersebut dan peta-peta tematik. Alat-alat yang digunakan yakni alat tulis menulis, daftar quisioner, kalkulator dan komputer.
a. Luas kawasan hutan produksi
b. Produksi kayu Bulat
c. Jumlah IPHHK yang aktif

2) Variabel dependen (Endogen) adalah variabel yang mempengaruhi variabel eksogen. Variabel endogen dalam penelitian ini adalah produksi kayu gergajian.

\section{Jenis dan Sumber Data}

Jenis data yang digunakan pada penelitian ini adalah : Data kualitatif, dan Data kuantitatif. Sumber data yang digunakan dalam penelitian ini terdiri dari data primer dan data sekunder. besarnya hubungan dan pengaruh variabel independen yang jumlahnya lebih dari dua. 
Adapun persamaan model regresi berganda tersebut adalah :

$$
\mathrm{Y}=\mathrm{a}+\mathrm{b}_{1} \mathrm{X}_{1}+\mathrm{b}_{2} \mathrm{X}_{2}+\ldots .+\mathrm{b}_{\mathrm{k}} \mathrm{X}_{\mathrm{k}}
$$

Keterangan :

Y : nilai prediksi dari $\mathrm{Y}$

A : bilangan konstan

$b_{1}, b_{2}, \ldots . . b_{k} \quad$ : Koefisien variabel bebas

$\mathrm{X}_{1}, \mathrm{X}_{2}$ : Variabel independen

Mendeteksi variabel $\mathrm{X}$ dan $\mathrm{Y}$ yang akan dimasukkan (entry) pada analisa regresi di atas dengan bantuan software Excel atau SPSS. Hasil analisis yang diperoleh harus dilakukan interpretasi (mengartikan), dalam interpretasinya pertama kali yang dilihat adalah nilai F-hitung, karena F-hitung menunjukan uji secara simultan (bersamasama) dalam arti variabel $X_{1}, X_{2}, \ldots X_{n}$ secara bersama-sama mempengaruhi terhadap Y.

\section{Uji hipotesis}

Uji Signifikan Simultan (Uji F), digunakan untuk menguji pengaruh variabel bebas secara bersama-sama terhadap variabel terikat.

$$
F_{\text {hitung }}=\frac{R^{2}(k-1)}{\left(1-R^{2}\right) /(N-k)}
$$

Adapun langkah-langkah uji $F$ atau uji simultan adalah :

\section{Perumusan Hipotesis}

$\mathrm{H}_{\mathrm{o}}$ : Diduga variabel produksi kayu bulat $\left(\mathrm{X}_{1}\right)$, jumlah IPHHK yang aktif $\left(\mathrm{X}_{2}\right)$ secara bersama-sama tidak

\section{Kriteria penolakan atau penerimaan}

Ho diterima jika :

a. $\mathrm{F}_{\text {hitung }} \leq \mathrm{F}_{\text {tabel }}$ maka $\mathrm{Ho}$ diterima dan $\mathrm{Ha}$ ditolak ini berarti tidak terdapat pengaruh simultan oleh variabel $\mathrm{X}$ dan $\mathrm{Y}$.

b. $F_{\text {hitung }} \geq F_{\text {tabel }}$ maka Ho ditolak dan $\mathrm{Ha}$ diterima hal ini berarti terdapat pengaruh

\section{Koefisien Determinasi $\left(\mathbf{R}^{2}\right)$}

Koefisien determinasi menunjukkan suatu proporsi dari varian yang dapat diterangkan berpengaruh terhadap produksi kayu gergajian.

$\mathrm{H}_{1}$ : Diduga variabel produksi kayu bulat $\left(\mathrm{X}_{1}\right)$, jumlah IPHHK yang aktif $\left(\mathrm{X}_{2}\right)$ secara bersama-sama berpengaruh terhadap produksi kayu gergajian.

yang simultan terhadap variabel $\mathrm{X}$ dan Y.

Uji signifikansi parsial (uji t) atau uji individu digunakan untuk menguji apakah suatu variabel bebas berpengaruh atau tidak terhadap variabel terikat

oleh persamaan regresi terhadap varian total. Besarnya koefisien determinasi dirumuskan sebagai berikut : 


$$
R^{2}=\frac{n\left(a \cdot \sum y+b 1 \cdot \sum y x 1+b 2 \cdot \sum y x 2+b 3 \cdot \sum y x 3\right)-\left(\sum Y\right)^{2}}{n \cdot \sum y^{2}-\left(\sum y\right)^{2}}
$$

\section{HASIL DAN PEMBAHASAN}

\section{Luas Hutan di Provinsi Maluku.}

Luas Kawasan Hutan di Provinsi

Maluku berdasarkan Keputusan Menteri Lingkungan Hidup dan Kehutanan Nomor : 854/Menhut-II/2014 tanggal 29 September 2014 skala 1:250.000 adalah 3.919.617 Ha, yang terdiri dari hutan Konservasi seluas 429.538 ha (10,96\%), Hutan Lindung 627.256 ha $(16,01 \%)$, Hutan Produksi Terbatas
894.258 ha $(22,81 \%)$, Hutan Produksi tetap 643.699 ha $(16,42 \%)$ dan Hutan Produksi Konversi 1.324 .866 ha $(33,80 \%)$. Luas Hutan berdasarkan fungsi dapat dilihat pada Gambar 1. sedangkan luas kawasan hutan per kabupaten/Kota di provinsi maluku dirincikan pada Tabel 1.

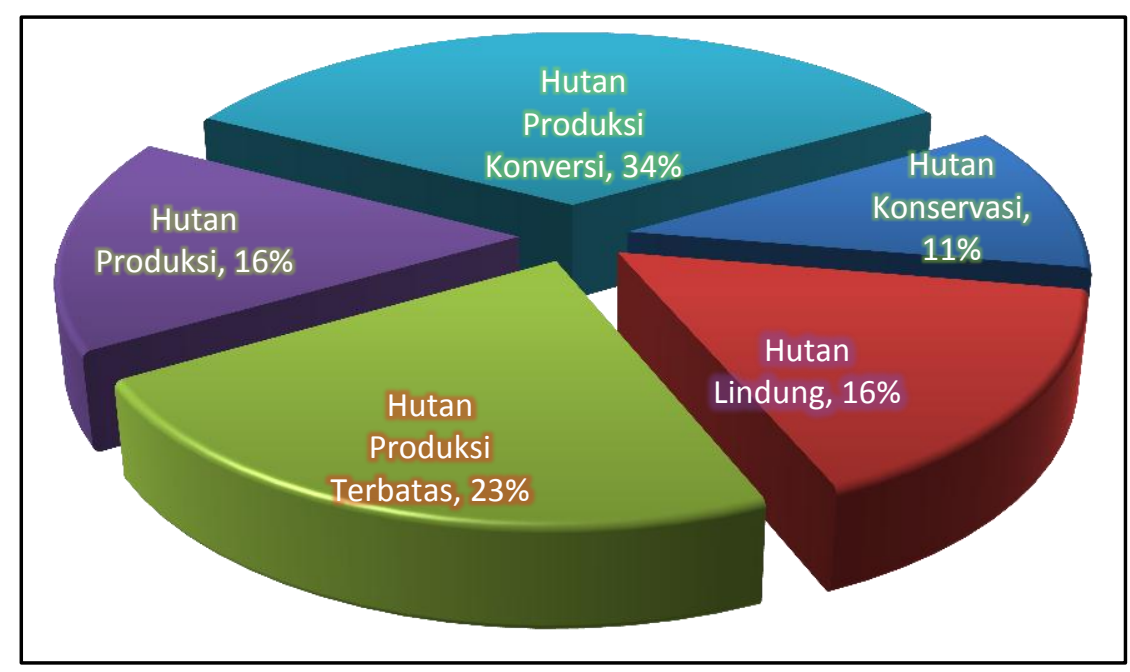

Gambar 1. Persentase Luas Kawasan Hutan Berdasarkan Fungsi 
Tabel 1. Luas Kawasan Hutan Di Provinsi Maluku

\begin{tabular}{|r|l|r|r|r|r|r|r|r|}
\hline \multirow{2}{*}{ No } & \multirow{2}{*}{$\begin{array}{c}\text { Kabupaten / } \\
\text { Kota }\end{array}$} & $\begin{array}{c}\text { Hutan } \\
\text { Konservasi }\end{array}$ & $\begin{array}{c}\text { Hutan } \\
\text { Lindung }\end{array}$ & $\begin{array}{c}\text { Hutan } \\
\text { Produksi } \\
\text { Terbatas }\end{array}$ & $\begin{array}{c}\text { Hutan } \\
\text { Produksi }\end{array}$ & $\begin{array}{c}\text { Hutan } \\
\text { Produksi } \\
\text { Konversi }\end{array}$ & $\begin{array}{c}\text { Jumlah } \\
\text { Luas }\end{array}$ & \% \\
\hline 1 & Ambon & - & 10.292 & & & - & 10.292 & 0,26 \\
\hline 2 & Malteng & 175.928 & 133.451 & 179.406 & 28.522 & 100.732 & 617.872 & 15,76 \\
\hline 3 & Buru & 6.849 & 108.166 & 109.951 & 106.912 & 95.556 & 427.434 & 10,90 \\
\hline 4 & Bursel & - & 73.118 & 101.652 & 90.768 & 79.604 & 345.142 & 8,81 \\
\hline 5 & Malra & 18.017 & 6.438 & 2.399 & 2.966 & 17.322 & 47.142 & 1,20 \\
\hline 6 & Tual & - & 9.173 & 987 & & 1.595 & 11.755 & 0,30 \\
\hline 7 & MTB & 77.198 & 13.010 & 78.165 & 112.045 & 138.049 & 419.467 & 10,70 \\
\hline 8 & MBD & 51.168 & 34.774 & 4.584 & 71.262 & 173.162 & 334.950 & 8,55 \\
\hline 9 & SBB & 32.226 & 124.699 & 156.045 & 9.810 & 91.632 & 414.412 & 10,57 \\
\hline 10 & SBT & 1.216 & 107.880 & 261.069 & 27.162 & 115.869 & 513.196 & 13,09 \\
\hline 11 & Aru & 67.103 & 6.254 & & 194.251 & 510.347 & 777.955 & 19,85 \\
\hline & Jumlah & 429.538 & 627.255 & 894.258 & 643.698 & 1.324 .868 & 3.919 .617 & 100 \\
\hline
\end{tabular}

Sumber : SK Kepmenlinghut Nomor .854/Menhut-II/2014

\section{Industri Primer Hasil Hutan Kayu}

Jumlah IPHHK di Provinsi Maluku Tahun 2017 sebanyak 80 unit badan usaha industri, primer yang aktif melakukan proses pengelolaan kayu olahan sebanyak 57 unit atau $70 \%$ dari jumlah keseluruhan yang dapat dilihat pada Tabel 2 .

Tabel 2. Perkembangan IPHHK di Provinsi Maluku Tahun 2017

\begin{tabular}{|c|c|c|c|c|c|c|c|}
\hline \multirow[b]{3}{*}{ No } & \multirow{3}{*}{$\begin{array}{c}\text { Kabupate } \\
\text { n / Kota }\end{array}$} & \multicolumn{6}{|c|}{ Kapasitas Produksi (Unit) } \\
\hline & & \multicolumn{2}{|c|}{$<2.000 \mathrm{M} 3 /$ thn } & \multicolumn{2}{|c|}{$2.000-6.000 \mathrm{M} 3 / \mathrm{thn}$} & \multicolumn{2}{|c|}{$>6.000 \mathrm{M} 3 / \mathrm{thn}$} \\
\hline & & $\begin{array}{l}\text { Jumla } \\
\text { h Unit }\end{array}$ & $\begin{array}{l}\text { Kapasitas } \\
\text { Izin } \\
\text { Produksi }\end{array}$ & $\begin{array}{l}\text { Jumlah } \\
\text { Unit }\end{array}$ & $\begin{array}{c}\text { Kapasitas } \\
\text { Izin Produksi }\end{array}$ & $\begin{array}{l}\text { Jumlah } \\
\text { Unit }\end{array}$ & $\begin{array}{c}\text { Kapasitas } \\
\text { Izin Produksi }\end{array}$ \\
\hline 1 & Ambon & 5 & 3.600 & 2 & 3.150 & - & - \\
\hline 2 & Malteng & 30 & 30.400 & 4 & 11.500 & - & - \\
\hline 3 & Buru & 5 & 4.850 & 2 & 18.000 & 1 & 42.000 \\
\hline 4 & Bursel & - & - & 5 & 19.300 & - & - \\
\hline 5 & Malra & - & - & - & - & - & - \\
\hline 6 & Tual & - & - & - & - & - & - \\
\hline 7 & MTB & - & - & 1 & 4.000 & - & - \\
\hline 8 & MBD & 3 & 2.100 & - & - & - & - \\
\hline 9 & SBB & 13 & 12.150 & 3 & 10.000 & - & - \\
\hline 10 & SBT & 3 & 4.000 & 3 & 16.000 & - & - \\
\hline \multirow[t]{2}{*}{11} & Aru & - & - & - & - & - & - \\
\hline & Jumlah & 59 & 57.100 & 20 & 81.950 & 1 & 42.000 \\
\hline
\end{tabular}

Sumber : Statistik Dinas Kehutanan Provinsi Maluku, 2017 
Jika dilihat dari perkembangan tahun sebelumnya maka perkembangan IPKHH di Provinsi Maluku cenderung relatif stabil.

Tabel 3. Perkembangan IUPHHK di Provinsi Maluku Tahun 2014-2017

\begin{tabular}{ccccl}
\hline \multirow{2}{*}{ Tahun } & \multicolumn{2}{c}{ IUPHHK } & & \multicolumn{1}{c}{ Keterangan } \\
& Aktif & $\begin{array}{c}\text { Tidak } \\
\text { Aktif }\end{array}$ & Jumlah & \\
\hline 2014 & 49 & 19 & 68 & Produksi Kayu Gergajian \\
2015 & 48 & 3 & 51 & sebagian besar berasal dari \\
2016 & 56 & 24 & 80 & APL/Hutan Hak \\
2017 & 57 & 23 & 80 & \\
\hline
\end{tabular}

Sumber : Statistik Dinas Kehutanan Provinsi Maluku, 2017

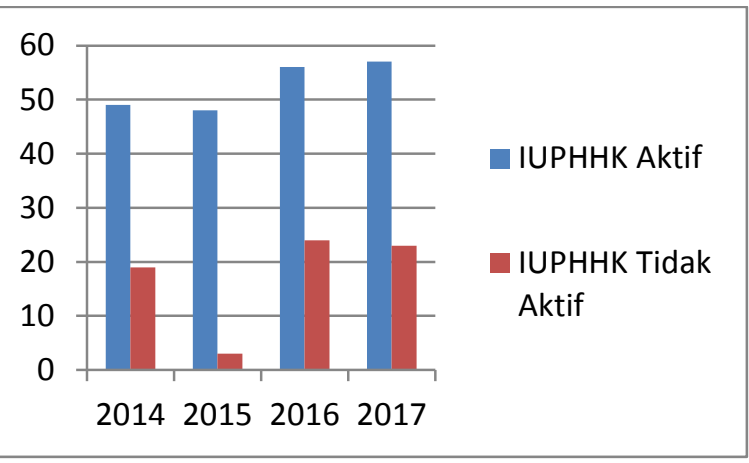

Gambar 2. Grafik perkembangan IUPHHK tahun 2014-2017

Kapasitas Produksi atau jumlah/kemampuan $\mathrm{p}$ roduksi maksimum setiap tahun yang diperken ankan,berdasarkan izin dari pejabat yang berwenang dibagi kedalam 3 kapasitas yaitu Kapasitas Produksi $<2.000$ menjadi kewenangan Bupati sebanyak 59 unit,

\section{Produksi Kayu Bulat}

Sejak pasca konflik sosial di Provinsi Maluku tahun 1999 dan mulai berakhir tahun 2006 maka pembangunan perumahan, kantor pemerintah, instansi dan badan lainnya
Kapasitas Produksi 2.000-6.000 menjadi kewenangan Pemerintah Provinsi sebanyak 20 unit sedangkan Kapasitas Produksi > 6.000 menjadi kewenangan Pusat/ kementerian sebanyak 1 unit

membutuhkan kayu untuk pembangunan, baik untuk rumah maupun untuk konstruksi bangunan sehingga di perkirakan setiap pembangunan rumah dibutuhkan kayu olahan sebanyak + $25 \mathrm{~m} 3 /$ rumah. Dan setiap tahun 
jumlah pemakaaian kayu di Kota Ambon mencapai $20.000 \mathrm{~m} 3 / \mathrm{thn}$.

Kayu olahan yang masuk ke IPHHK berasal dari Hutan Hak / Hutan Rakyat yang telah di kontrak suplai sebagai sumber Rencana Pemenuhan Bahan Baku Industri
(RPBBI) untuk IPHHK. Kayu Bulat yang bersumber dari hutan hak diolah menjadi swalap (ukuran $20 \mathrm{~cm} \quad \mathrm{x} 20 \mathrm{~cm} \quad \mathrm{x} \quad 3 / 4 \mathrm{~cm}$ ) kemudian di angkut ke industri IPHHK untuk dijadikan kayu olahan. Produksi Kayu Bulat menjadi Kayu Olahan dari IPHHK per Kabupaten dapat dilihat pada Tabel. 4

abel 4. Produksi Kayu Bulat menjadi Kayu Olahan IPHHK Tahun 2017

\begin{tabular}{llccc}
\hline NO & $\begin{array}{c}\text { KABUPATEN } \\
\text { / KOTA }\end{array}$ & $\begin{array}{c}\text { PRODUKSI } \\
\text { KB } \\
\left(\mathbf{m}^{3}\right)\end{array}$ & $\begin{array}{c}\text { PRODUKSI } \\
\text { KO } \\
\left(\mathbf{m}^{\mathbf{3}}\right)\end{array}$ & $\begin{array}{c}\text { RENDEMEN } \\
(\mathbf{\%})\end{array}$ \\
\hline 1 & Malteng & $1.452,6094$ & $1.016,8266$ & 70,00 \\
2 & Malra & - & - & - \\
3 & Buru & 132,9342 & 84,3080 & 63,42 \\
4 & MTB & - & - & - \\
5 & Ambon & - & - & - \\
6 & Aru & 345,0000 & 241,2608 & 69,93 \\
7 & SBB & 850,6541 & 567,5229 & 66,72 \\
8 & SBT & 80,8766 & 55,9860 & 69,22 \\
9 & Bursel & 98,4332 & 66,0325 & 67,08 \\
10 & MBD & - & - & - \\
11 & Tual & - & - & - \\
\hline
\end{tabular}

Berdasarkan Tabel 7, diatas terlihat bahwa Rendemen kayu bulat diperkirakan sebesar $68,63 \%$. hal ini sama dengan Permen LHK Nomor : P.43/Menlhk-Setjen/2015 dengan Rendemen yang diperkenankan dari pada kayu bulat sebesar antara 60\%-70\%. Kecilnya nilai rendemen disebabkan karena tataletak pohon waktu ditebang serta kemampuan operator Chain saw dalam mengelola kayu.

Jika dilihat dari perkembangan tahun sebelumnya maka perkembangan produksi kayu bulat di Provinsi Maluku terlihat menurun secara siqnifikan. Perkembangan produksi kayu bulat di Provinsi Maluku dapat di lihat pada Tabel 4 dan gambar 3 . 
Tabel 5. Produksi kayu bulat tahun 2014-2017

\begin{tabular}{crr}
\hline Tahun & $\begin{array}{c}\text { Produksi Kayu } \\
\text { Bulat }\left(\mathbf{m}^{\mathbf{3}}\right)\end{array}$ & Keterangan \\
\hline 2014 & $259.537,17$ & \\
2015 & $306.738,93$ & \\
2016 & $300.219,68$ & \\
2017 & $2.960,51$ & \\
\hline
\end{tabular}

Hampir sebagian besar kayu yang berasal dari hutan hak/ Hutan Rakyat di suplay ke Industri dari pada di jual dalam bentuk logs kepada industri-industri besar karena keterbatasan peralatan dan permodalan.

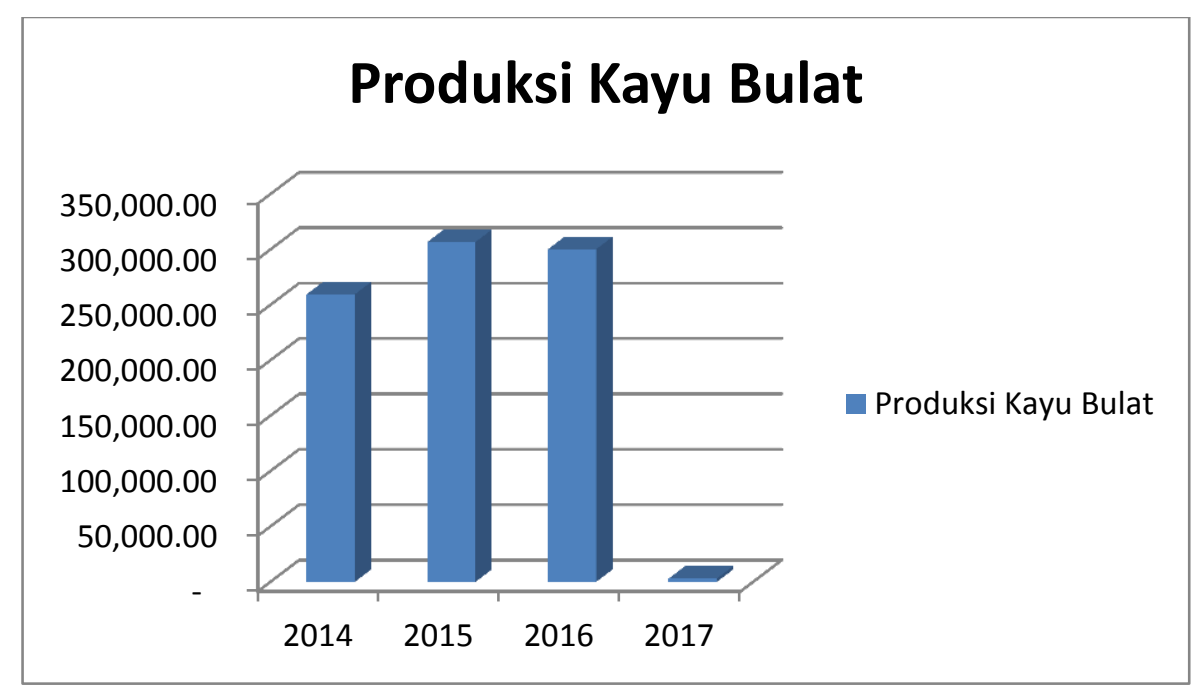

Gambar 3. Grafik Produksi Kayu Bulat

\section{Produksi Kayu Gergajian}

Berdasarkan pemantauan Produksi kayu gergajian di Provinsi Maluku sejak 4 tahun terakhir, terus menurun sebesar $87 \%$. Tahun 2014 jumlah produksi kayu olahan
$16.193 \mathrm{~m}^{3}$ dan pada tahun 2017 jumlah produksi kayu olahan $2.081 \mathrm{~m}^{3}$. Jumlah Produksi kayu gergajian di Provinsi Maluku dapat dilihat pada Tabel 6 . 
Tabel 6. Produksi Kayu Gergajian di Provinsi Maluku Tahun 2014 - 2017

\begin{tabular}{cccccc}
\hline \multirow{2}{*}{ NO } & KABUPATEN / & \multicolumn{4}{c}{ TAHUN $\left(\mathbf{m}^{\mathbf{3}}\right)$} \\
\cline { 3 - 6 } & KOTA & $\mathbf{2 0 1 4}$ & $\mathbf{2 0 1 5}$ & $\mathbf{2 0 1 6}$ & $\mathbf{2 0 1 7}$ \\
\hline 1 & Malteng & $3.610,37$ & - & $2.828,43$ & $1.016,83$ \\
2 & Malra & - & $3.526,87$ & - & - \\
3 & Buru & $3.450,18$ & 270,81 & $2.981,29$ & 84,31 \\
4 & MTB & - & - & - & - \\
5 & Ambon & 611,62 & - & - & - \\
6 & Aru & - & - & - & 241,26 \\
7 & SBB & $2.397,53$ & $3.123,53$ & $3.357,03$ & 567,53 \\
8 & SBT & $2.063,07$ & 20,52 & 210,08 & 55,99 \\
9 & Bursel & $2.175,38$ & - & 656,25 & 66,03 \\
10 & MBD & $1.885,60$ & - & - & - \\
11 & Tual & - & - & - & - \\
\hline & Jumlah & $16.193,7311$ & $7.141,7102$ & $10.033,0740$ & $2.031,9368$ \\
\hline
\end{tabular}

Sumber : Statistik Dinas Kehutanan Provinsi Maluku, 2017

\section{Analisis Produksi Hasil Hutan Kayu}

Hasil pengujian Model regresi Secara Simultan Untuk membuktikan hipotesis penelitian yang diajukan dalam penelitian ini, digunakan metode regresi linear dengan hasil analisis sebagai berikut :

Tabel 7. Hasil Analisis regresi Linier

\begin{tabular}{lccccc}
\hline Variabel Bebas $(\mathrm{X})$ & \multicolumn{2}{c}{ Koefisien Regresi } & $\mathrm{T}_{\text {Hitung }}$ & TSignifikan. & Keterangan \\
& $\mathrm{B}$ & Standar. Error & & \\
\hline Konstanta $\left(\beta_{0}\right)$ & 18060.117 & 65944.295 & .274 & .0830 & \\
Produksi Kayu Bulat & .022 & .037 & .597 & .0658 & Signifikan \\
Jumlah IPHHK & -267.326 & 1154.602 & -.232 & .0855 & Signifikan \\
\hline
\end{tabular}

\begin{tabular}{ccccc}
\hline Model & R & R kuadrat & $\begin{array}{c}\text { Adjusted R } \\
\text { kuadrat }\end{array}$ & Standart Galat \\
\hline 1 & 0.7 & 0.478 & -0.567 & 7396.98736 \\
\hline
\end{tabular}


Tabel 8. analisis of varians

\begin{tabular}{lccccc}
\hline \multicolumn{1}{c}{ Model } & $\begin{array}{c}\text { Jumlah } \\
\text { Kuadrat }\end{array}$ & db & Kuadrat Tengah & F & Sig. \\
\hline Regresi & 50.020 .790 .818 & 2 & 25010395.409 & 0.457 & $0.723^{\text {b }}$ \\
Galat & 54.715 .421 .932 & 1 & 54715421.932 & & \\
\hline Total & 104.736 .212 .75 & 3 & & & \\
\hline
\end{tabular}

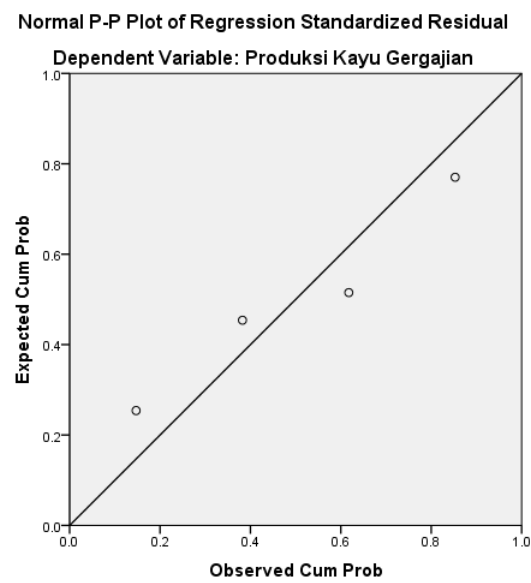

Gambar 4. Kurva Regresi Linier

Dari persamaan Regresi di atas dapat dijelaskan sebagai berikut :

- Konstanta -18.057; artinya jika produksi kayu bulat $\left(\mathrm{X}_{1}\right)$ dan jumlah IPHHK $\left(\mathrm{X}_{2}\right)$ nilainya adalah 0 , maka produksi kayu gergajian (Y) nilainya adalah 18.057

- Koefisien regresi variabel produksi kayu bulat $\left(\mathrm{X}_{1}\right)$ sebesar 0,02 ; artinya jika variabel independen lain nilainya tetap dan produksi kayu bulat

\section{KESIMPULAN DAN SARAN}

\section{Kesimpulan}

1. Perhitungan jumlah kebutuhan kayu olahan berdasarkan kapasitas ijin industri dan peredaran kayu olahan mengalami kenaikan $1 \%$ maka produksi kayu gergajian akan mengalami kenaikan sebesar 0,02

Koefisien regresi variabel jumlah IPHHK sebesar -267,28; artinya iika variabel independen lain nilainya tetap dan jumlah IPHHK mengalami penurunan maka akan menurunkan produksi kayu gergajian sebesar 267,28. Semakin banyak IPHHK maka semakin naik jumlah produksi kayu gergajian.

berdasarkan database hasil hutan, maka diketahui Provinsi Maluku mampu memenuhi kebutuhan bahan baku kayu olahan di Provinsi Maluku. 
Data peredaran hasil hutan kayu olahan dijadikan dasar dalam menentukan kebutuhan ril pada industri mebel dibandingkan dengan jumlah peredaran kayu olahan hasil hutan.

2. Pengaruh produksi kayu bulat dan jumlah IPHHK (variabel independen) terhadap produksi kayu gergajian (variabel dependen) sebesar 47\%,

\section{Saran}

Berdasarkan hasil penelitian maka rekomendasi saran adalah :

1) Perlunya mempertahankan keberadaan usaha pengelolaan hasil hutan kayu dan meningkatkan produksi kayu olahan/ gergajian;

\section{DAFTAR PUSTAKA}

Alam Setia Zain, 2000, Hukum Lingkungan Konservasi Hutan, PT. Rineka Cipta, ISBN : 979-518-687-6 Jakarta

Biro Kepegawaian Sekretaris Jenderal Departemen Kehutanan, 2005 Petunjuk jabatan Fungsional Polisi Kehutanan dan Angka kreditnya, Jakarta

Drajad Kurniadi, 2006 Pemantauan Peredaran Hasil Hutan di Provinsi Jambi, Institut Pertanian Bogor. Bogor.

I Gusti Nyoman. A, 2007 Perlindungan Hutan, Kerusakan Hutan Tanya Kenapa Buku Majalah Kehutanan Indonesia edisi IX Tahun 2007.

Peraturan Menteri Kehutanan Nomor: P.42/Menhut-II/2014 tentang Penatausahaan Hasil Hutan Kayu yang berasal dari Hutan Tanaman pada Hutan Produksi artinya data produksi kayu bulat dan jumlah IPHHK (variabel independen) mampu menjelaskan variasi variabel dependen (produksi kayu gergajian) sebesar $47 \%$. Sedangkan sisanya sebesar $53 \%$ di pengaruhi atau dijelaskan oleh variabel lain yang tidak dimasukan dalam model penelitian ini.

2) Perlu adanya penelitian dan pengembangan model terkait pemanfaatan hutan yang tidak produktif menjadi hutan tanaman yang dapat memenuhi kebutuhan bahan baku indutri yang sangat luas

Peraturan Menteri Lingkungan Hidup dan Kehutanan Nomor: P.13/MenlhkII/2015 tentang Ijin Usaha Industri Primer Hasil Hutan.

Peraturan Menteri Lingkungan Hidup dan Kehutanan Nomor : P.60/MenlhkSetjen/Kum.1/2016 tentang Perubahan atas Permenlhk Nomor : P.43/Menlhk-Setjen/2015 tentang Penatausahaan Hasil Hutan Kayu yang berasal dari Hutan Alam

Peraturan Pemerintah RI Nomor : 45 Tahun 2004 tentang Perlindungan Hutan

Salim HS, 2003 Dasar-Dasar Hukum Kehutanan, sinar Grafika ISBN : 979-8767-91-8 Jakarta

Undang-Undang RI Nomor : 05 Tahun 1990 tentang Konservasi Sumber Daya Alam

Undang-Undang RI Nomor : 41 Tahun 1999 tentang Kehutanan. 